\title{
Gas sensing application of nanocrystalline zinc oxide thin films prepared by spray pyrolysis
}

\author{
NISHA $R^{1, *}$, K N MADHUSOODANAN ${ }^{1}$, T V VIMALKUMAR ${ }^{2}$ and K P VIJAYAKUMAR ${ }^{3}$ \\ ${ }^{1}$ Department of Instrumentation, Cochin University of Science and Technology, Cochin 682 022, India \\ ${ }^{2}$ Department of Physics, St. Thomas' College, Thrissur 680001, Kerala \\ ${ }^{3}$ Thin Film Photovoltaic Division, Department of Physics, Cochin University of Science and Technology, Cochin 682022 , \\ India
}

MS received 10 November 2014; revised 14 January 2015

\begin{abstract}
Nanocrystalline oxygen-deficient $\mathrm{ZnO}$ thinfilm sensors were prepared by spray pyrolysis technique using zinc acetate dissolved in propanol and water as precursor. Response of the sensor to target gases $\mathrm{NO}_{2}$ and $\mathrm{H}_{2} \mathrm{~S}$ is studied. At optimum temperature of $200^{\circ} \mathrm{C}$, the sensors have a response of 3.32 to 7 ppm $\mathrm{NO}_{2}$ and 1.4 to 18 ppm of $\mathrm{H}_{2} \mathrm{~S}$ gas. The analytical characterizations of the prepared sensors were performed using X-ray diffraction measurement, scanning electron microscopy, energy-dispersive X-ray spectroscopy and Raman spectroscopy. Dynamic response of sensors to different concentrations of $\mathrm{NO}_{2}$ and $\mathrm{H}_{2} \mathrm{~S}$ gas was tested at optimum temperature. Experimental data revealed the sensors to be more selective to $\mathrm{NO}_{2}$ gas with satisfactory response and recovery time.
\end{abstract}

Keywords. ZnO; thin film; spray pyrolysis; gas sensor; $\mathrm{NO}_{2} ; \mathrm{H}_{2} \mathrm{~S}$.

\section{Introduction}

Monitoring air quality has become a priority due to the great amounts of pollutants released in the atmosphere, which have a toxic effect on ecosystem. To detect pollutant gases different kinds of sensor have been developed, i.e., electrochemical sensors, ${ }^{1}$ polymer sensors, ${ }^{2}$ surface acoustic wave (SAW) sensors $^{3}$ and metal oxide semiconductor (MOS) sensors. ${ }^{4}$ The last ones are being preferred mainly because of their simplicity, small dimension and low cost. Conductometric metal oxide gas sensors rely on changes of electrical conductivity due to the interaction with the surrounding atmosphere. ${ }^{5}$ In 1991, Yamazoe ${ }^{6}$ demonstrated that reduction in crystal size would significantly increase the sensor performance. Nano-sized grains of metal oxides are almost depleted of carriers (most carriers are trapped in surface states) and exhibit much poorer conductivity than micro-sized grains in ambient air; hence, when exposed to target gases, they exhibit greater conductance changes as more carriers are activated from their trapped states to the conduction band than with micro-sized grains. Moreover, the large surface to volume ratio of nanomaterials exhibits high sensitivity to target gases. Hence, in the recent years, researchers are working towards the development of MOS nanomaterial-based sensor elements with improved sensing performance.

\footnotetext{
*Author for correspondence (rnisha.r3@gmail.com)
}

$\mathrm{ZnO}$ is a material with a variety of potential applications such as electronics, ${ }^{7}$ photonics, ${ }^{8}$ acoustics, ${ }^{9}$ TCO layer in solar cell ${ }^{10,11}$ and sensing. ${ }^{12}$ On the electronic side, $\mathrm{ZnO}$ holds some potential in transparent thin film transistors owing to its high optical transmittivity and high conductivity. In optical emitters, its high exciton binding energy (60 $\mathrm{meV})^{13}$ gives $\mathrm{ZnO}$ an edge over other semiconductors such as GaN. ${ }^{14}$ Due to its large electrochemical coupling, $\mathrm{ZnO}$ has significant applications in acoustic wave devices as SAW filter. As a gas sensing material, it is one of the earliest discovered and the most widely applied oxide gas sensing material. ${ }^{15} \mathrm{ZnO}$-based elements have attracted much attention as gas sensors because of their chemical sensitivity to different adsorbed gases, high chemical stability, amenability to doping, nontoxicity and low cost. Over the years various researchers have used different forms of $\mathrm{ZnO}$ for the detection of many gases. Pure and doped $\mathrm{ZnO}$ films prepared by different methods were found to be sensitive to $\mathrm{H}_{2} \mathrm{~S}$ gas. ${ }^{16-20} \mathrm{ZnO}$-based gas sensors were also found to be suitable for detection of gases like methane, ${ }^{21,22}$ formaldehyde, ${ }^{23-25}$ ethanol, $^{26-29}$ ammonia, ${ }^{30-34} \mathrm{LPG},{ }^{35-37}$ methanol, ${ }^{38}$ propanol, ${ }^{38,39}$ and $\mathrm{NO}_{2} \cdot{ }^{18,40-44}$

In the present context we report the $\mathrm{NO}_{2}$ and $\mathrm{H}_{2} \mathrm{~S}$ gas sensing characteristics of oxygen-deficient nanocrystalline zinc oxide films prepared by chemical spray pyrolysis (CSP) technique on glass substrates. Sensor behaviour is presented in detail for a representative concentration for $7 \mathrm{ppm} \mathrm{NO}_{2}$ and $18 \mathrm{ppm} \mathrm{H}_{2} \mathrm{~S}$ gas. Gas sensing performance of the sensors to test gases was investigated in the temperature range of $100-225^{\circ} \mathrm{C}$. 


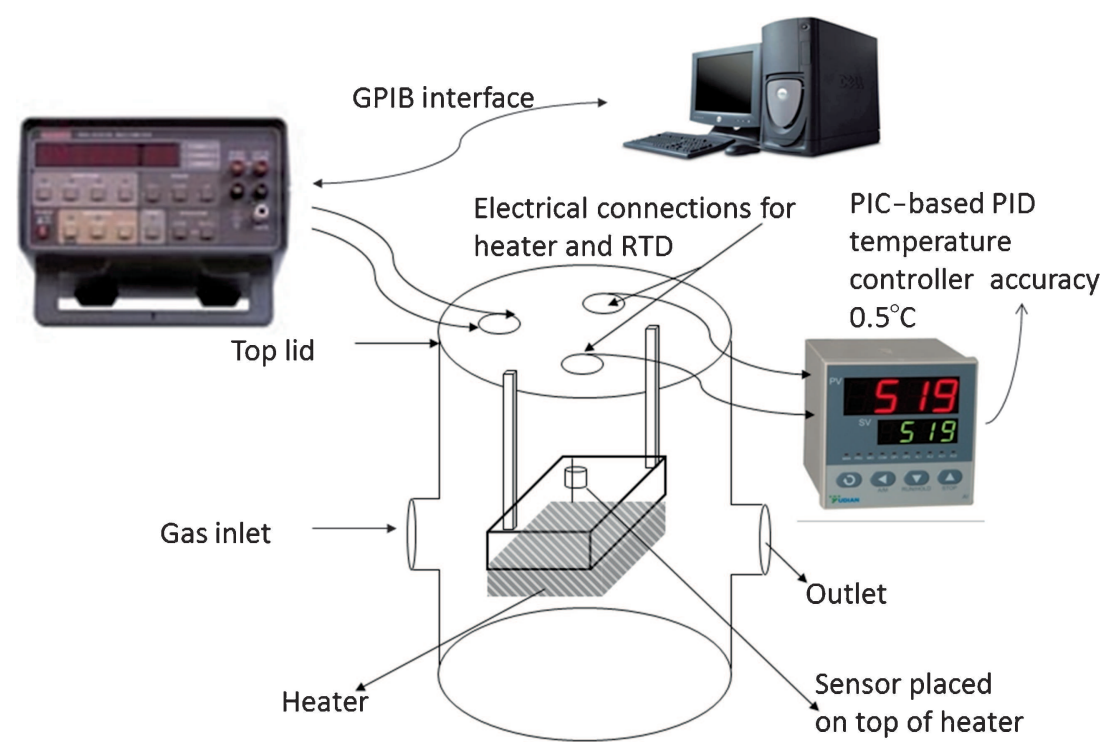

Figure 1. Schematic representation of static test system.

\section{Materials and methods}

\subsection{Film preparation}

Zinc oxide thin films were prepared on soda lime glass substrate using CSP technique. Zinc acetate solution (0.3 M) was prepared in a mixture of propanol and water, taken in the volume ratio 1:1. This precursor was selected due to its high vapour pressure at low temperature. Addition of few drops of acetic acid prohibits the precipitation of zinc hydroxide, thereby making the spray solution clear and producing films of better optical transmittance. Quantity of acetic acid added to the solution is also a key parameter in the film deposition process. Compressed air was used as the carrier gas (pressure $\sim 0.34$ bar) and temperature of substrate was kept at $450 \pm 5^{\circ} \mathrm{C}$. Now keeping the molarity of zinc acetate $\left(\mathrm{Zn}\left(\mathrm{CH}_{3} \mathrm{CO}_{2}\right) \cdot 2 \mathrm{H}_{2} \mathrm{O}\right)$ at $0.3 \mathrm{M}$ and spray rate at $7 \mathrm{ml} \mathrm{min}{ }^{-1}$, deposition was done using automated spray machine in which the spray rate, deposition time and movement of the spray head were controlled by a microprocessor. After the deposition, samples were quickly removed from the substrate heater. ${ }^{45} \mathrm{ZnO}$ films were deposited with $\sim 550 \mathrm{~nm}$ thickness over $30 \mathrm{~cm}^{2}$ area. $\mathrm{ZnO}$ films for gas sensing application were selected after optimizing the various parameters like spray rate, molarity, oxygen stoichiometry and thickness. ${ }^{46-48}$ Prior to gas sensing measurements, the films were annealed at an approximate temperature $600^{\circ} \mathrm{C}$ overnight (Actual temperature at the sample was within a range of $5 \%$ of this set temperature.) to remove any possible organic residue remained from the precursor solution and also to improve the crystallinity and to sinter the layer. High temperature annealing also helps in avoiding posterior instabilities, as these sensors are to be operated at elevated temperatures. For the purpose of gas sensing investigations, the films were cut into small pieces with an approximate area of $1 \mathrm{~cm}^{2}$.

\subsection{Gas sensing measurement setup}

The gas sensing measurements of the thin film sensor were carried out on custom-built static gas characterization system. The schematic representation of test system is shown in figure 1. The test system consists of a stainless steel chamber of diameter 7.5 and $6.35 \mathrm{~cm}$ height. The effective volume of the chamber is $280 \mathrm{ml}$. An inlet is provided for inserting the desired concentration of the gas to the chamber. The gas is injected into the test chamber with a syringe through the inlet provided with septum. Electrical connections from the sensor are taken with the help of two thin copper wires, bonded to the sensor with silver paint. The distance between the two electrodes is adjusted to $5 \mathrm{~mm}$. The sensing capability of the sensor is characterized at different operating temperatures with a precisely controlled heater $\left( \pm 0.5^{\circ} \mathrm{C}\right)$ inside the system, to find out the optimum working temperature. Resistance change of the sensor on introduction of the test gas into the chamber is measured using computercontrolled Keithley 195A digital multimeter. Gas concentration is measured by taking required amount of gas from the obtained precalibrated cylinder (Chemtron Science Laboratories) in a syringe and then injecting it into the chamber pre-filled with air at atmospheric pressure. The response of the sensor was studied at different operating temperatures in the range $100-225^{\circ} \mathrm{C}$ for various concentrations of $\mathrm{NO}_{2}$ and $\mathrm{H}_{2} \mathrm{~S}$ gas ranging from 1.5 to $30 \mathrm{ppm}$ and 5 to $60 \mathrm{ppm}$ in air, respectively.

\subsection{Characterization of the $\mathrm{ZnO}$ film}

The crystalline structure and particle size of annealed thin film sensor were examined by X-ray diffraction measurement (XRD, Bruker AXS D8 Advance). Surface morphology of the prepared sensors were analysed using scanning 


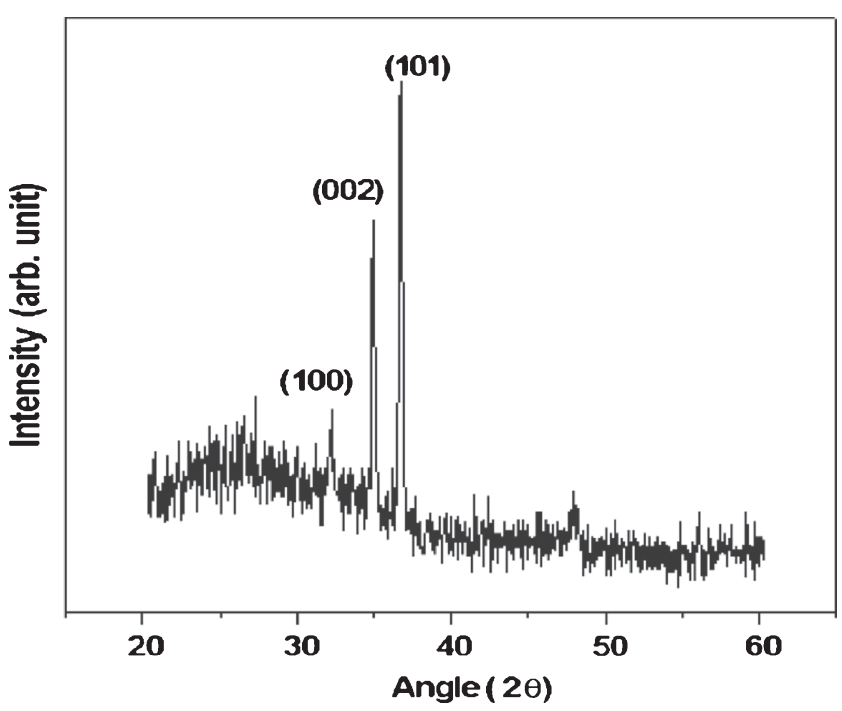

Figure 2. XRD pattern of annealed $\mathrm{ZnO}$ thin film sensor.

electron microscopy (SEM, JEOL Model JSM-6390LV). Elemental composition of the sensors was performed using energy-dispersive X-ray spectroscopy (EDS, JEOL Model JED-2300). Raman scattering measurements were obtained using Horiba Jobin Yvon LabRam HR system at a spatial resolution of $2 \mathrm{~mm}$ in a backscattering configuration. The 514.5 $\mathrm{nm}$ line of argon ion laser was used for excitation.

\section{Result and discussion}

\section{$3.1 X R D$}

Crystalline structure analysis of the prepared sensors was performed using XRD. Figure 2 shows the XRD pattern of annealed sensor. All peaks can be confirmed to correspond to the hexagonal wruzite structure of $\mathrm{ZnO}$ (JCPDS No. 361451). Main reflections were obtained in the $\left(30^{\circ}-40^{\circ}\right) 2 \theta$ range corresponding to (100), (002) and (101) planes, the (101) plane being prominent. Under the reactive conditions adopted in our experiments, the $\mathrm{ZnO}$ films tend to grow along the maximum density (101) plane. Earlier reports by Fan et al ${ }^{49}$ proved that the presence of thin film stress can alter the energetic balance between $\left(\begin{array}{lll}0 & 0\end{array}\right)$ and $\left(\begin{array}{lll}10 & 1\end{array}\right)$ orientations and lead to preferred $(101)$ texture in certain conditions. ${ }^{49,50}$

The crystallite size $(D)$ was calculated from peak broadening using the Scherrer approximation, which is defined as

$$
D=\frac{0.9 \lambda}{B \cos \theta}
$$

where $\lambda$ is the wavelength of the X-ray (1.5418 $\AA$ ), $B$ the full-width at half maximum (FWHM, radian) and $\theta$ the Bragg angle (degree). The crystallite sizes were calculated using FWHM of the peaks corresponding to the planes (10 $0),\left(\begin{array}{lll}0 & 0 & 2\end{array}\right)$ and ( $\left(\begin{array}{lll}1 & 0 & 1\end{array}\right)$. The average crystallite size was found

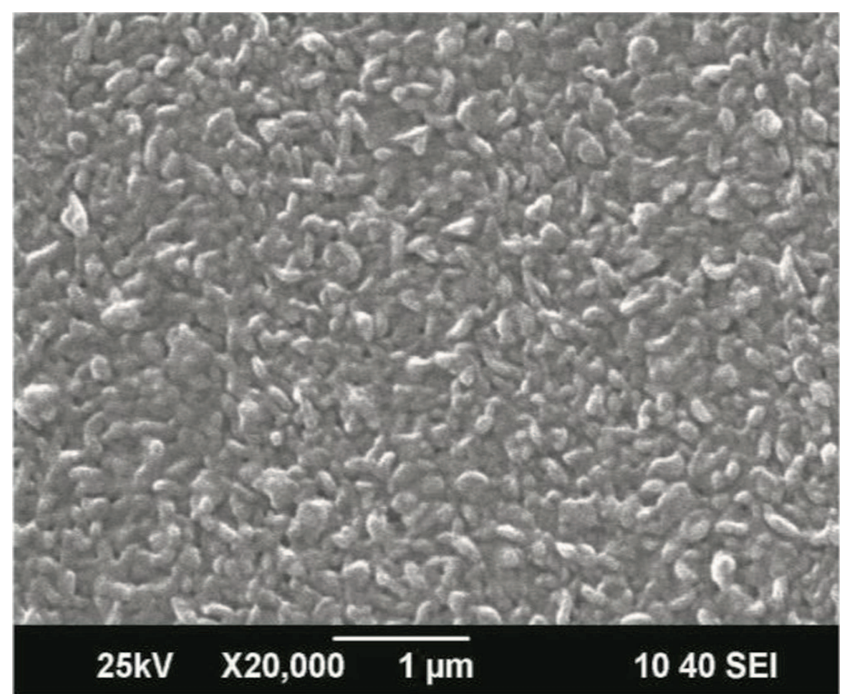

Figure 3. SEM images of annealed $\mathrm{ZnO}$ thin film sensor.

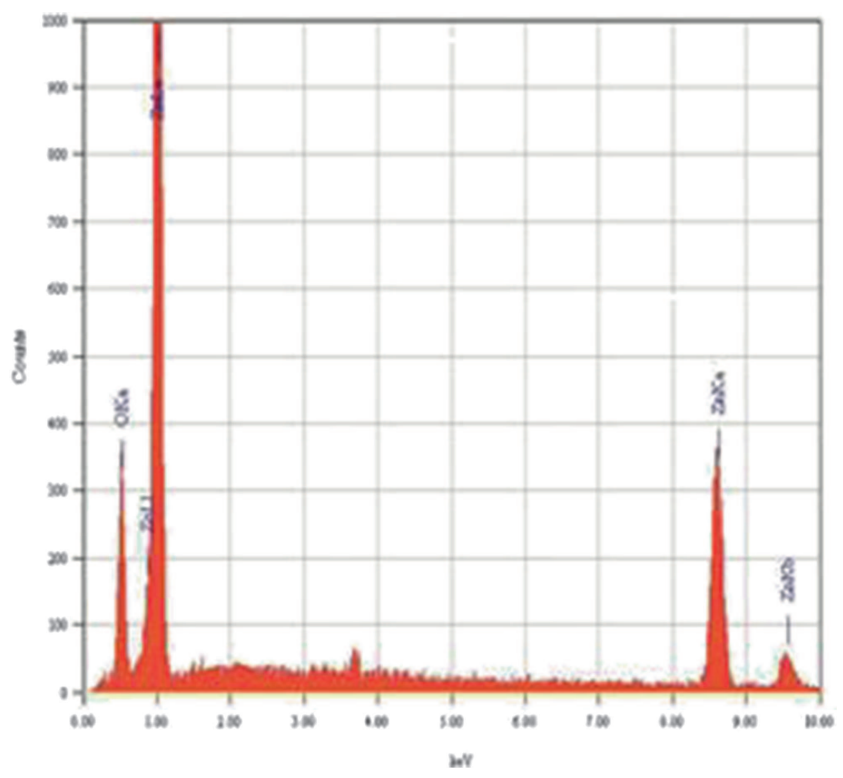

Figure 4. EDS spectrum of annealed $\mathrm{ZnO}$ thin film sensor.

to be $38 \mathrm{~nm}$. The XRD studies confirmed the nanocrystalline nature of thin film sensor.

\subsection{SEM and EDS}

SEM image of the annealed sensor shown in figure 3 revealed a closely packed arrangement of crystallites. Particles with not much definite shape were revealed in the SEM images of annealed thin film sensor. The EDS analysis of sensor is shown in figure 4. EDS analysis of annealed $\mathrm{ZnO}$ film shows that zinc and oxygen are the only detected elements. The SEM image provided a rough representation of the annealed thin film sensor. The EDS analysis performed proved that the prepared sensor film composed of zinc and oxygen 
elements only. The XPS analysis performed on the $\mathrm{ZnO}$ film is reported elsewhere. ${ }^{45}$

\subsection{Raman spectroscopy}

Raman spectrum of annealed thin film sensor is shown in figure 5. Raman spectroscopy gives information on vibrational properties of $\mathrm{ZnO} .{ }^{51} \mathrm{It}$ is known for wurtzite-type $\mathrm{ZnO}$ (space group $\mathrm{p} 6_{3} \mathrm{mc}$ ) that optical phonons at the $\Gamma$ point of the Brillouin zone belong to the following irreducible representation: $\Gamma=A_{1}+E_{1}+2 E_{2}+2 B_{1}$, where $A_{1}$ and $E_{1}$ modes are both Raman and infrared active, $E_{2}$ modes are Raman active only and $B_{1}$ modes are both Raman and infrared inactive (silent modes). ${ }^{13,52-54}$ Nonpolar $E_{2}$ phonon modes have two frequencies; the low frequency $E_{2}$ mode $\left(E_{2}^{\text {low }}\right)$ and high frequency $E_{2}$ mode $\left(E_{2}^{\text {high }}\right)$. The $E_{2}$ modes at low and high frequencies are at 101 and $437 \mathrm{~cm}^{-1}$, respectively. The low frequency $E_{2}$ mode $\left(E_{2}^{\text {low }}\right)$ is associated with vibration of the $\mathrm{Zn}$ sublattice, while the high frequency $E_{2}$ mode $\left(E_{2}^{\text {high }}\right)$ is related to the vibration of oxygen atoms. ${ }^{55,56} E_{2}^{\text {high }}$ of $\mathrm{ZnO}$ is the strongest mode in the wurtzite crystal structure. The strong $E_{2}$ (high) mode indicates a good crystallinity. ${ }^{57}$ Peak at $556 \mathrm{~cm}^{-1}$ is a contribution of the $E_{1}$ (LO) mode of $\mathrm{ZnO}$ in the case of oxygen deficiency. ${ }^{58,59}$ Such a strong intensity of $556 \mathrm{~cm}^{-1} E_{1}$ mode demonstrates that $\mathrm{ZnO}$ thin film sensor is oxygen deficient. These oxygendeficient sites can enhance the gas sensing properties of thin film sensor. An additional peak is obtained at $330 \mathrm{~cm}^{-1}$. Peak at the same position was reported earlier in literature by various researchers. ${ }^{60-62}$ This peak is assigned to possible multiple-phonon-scattering. The above presented results confirmed the $\mathrm{ZnO}$ hexagonal wurtzite structure, which is in good agreement with the obtained XRD results.

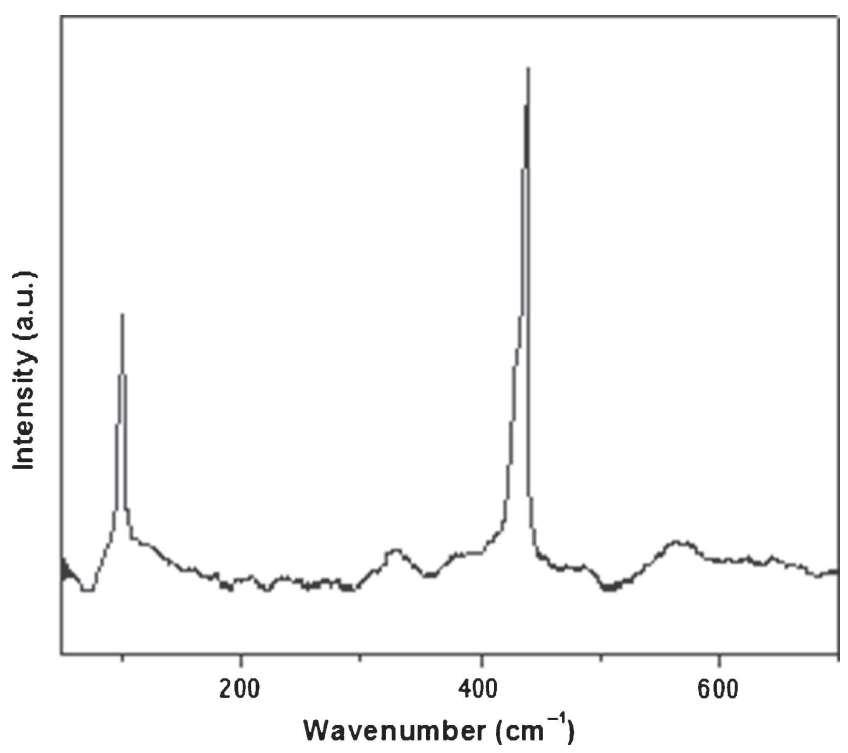

Figure 5. Raman spectra of annealed $\mathrm{ZnO}$ thin film sensor.

\subsection{Gas sensing investigations}

The gas sensing properties of thin film $\mathrm{ZnO}$ sensor was studied in a static gas sensing test system with an effective volume of $280 \mathrm{ml}$. Sensitivity of the active layer upon oxidizing $\mathrm{NO}_{2}$ gas exposure is measured in terms of the ratio $S=R_{\text {gas }} / R_{\text {air }}$ and for reducing gas $\left(\mathrm{H}_{2} \mathrm{~S}\right), S$ is given as $R_{\text {air }} / R_{\text {gas }}$, where $R_{\text {gas }}$ is resistance of sensor in presence of gas and $R_{\text {air }}$ is resistance of sensor before introduction of gas. The temperature-dependent sensitivity of sensors was studied in the range of $100-225^{\circ} \mathrm{C}$. Below the sensor temperature of $100^{\circ} \mathrm{C}$, it was difficult to measure gas sensing characteristics due to the sluggish recovery kinetics. Relatively low concentration $7 \mathrm{ppm}$ of $\mathrm{NO}_{2}$ and $18 \mathrm{ppm}$ $\mathrm{H}_{2} \mathrm{~S}$ gas investigation is presented in detail. Similar results were obtained for higher concentration studied. Figure $6 \mathrm{a}$ and $b$ represents temperature-dependent sensitivity of sensor

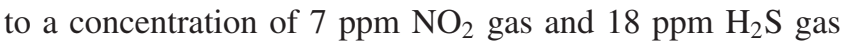
studied.

$\mathrm{NO}_{2}$ response of sensor to $7 \mathrm{ppm}$ presents a maximum sensitivity at $200^{\circ} \mathrm{C}$ as the temperature increases from 100 to $225^{\circ} \mathrm{C}$, the sensor sensitivity increasing from 1.22 to 3.32 , which is the maximum. Increasing the temperature above
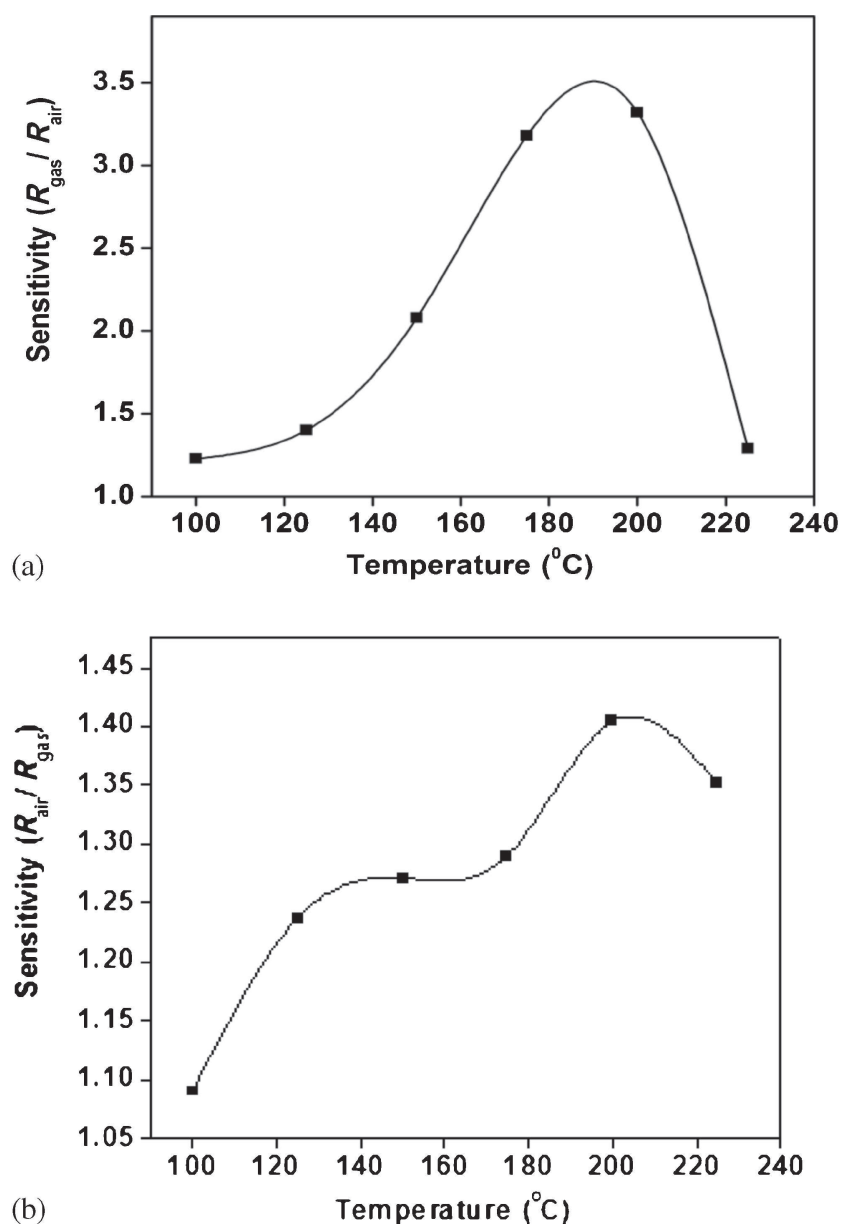

Figure 6. Sensitivity of $\mathrm{ZnO}$ thin film sensor towards (a) $7 \mathrm{ppm}$ of $\mathrm{NO}_{2}$ gas (b) $18 \mathrm{ppm}$ of $\mathrm{H}_{2} \mathrm{~S}$ gas at different temperatures. 
$200^{\circ} \mathrm{C}$ decreases sensor sensitivity, achieving 1.29 at $225^{\circ} \mathrm{C}$. Concerning the $18 \mathrm{ppm}_{2} \mathrm{~S}$ sensor response, sensitivity increases with increase of temperature in the studied range, attaining a maximum 1.4 at $200^{\circ} \mathrm{C}$. Increasing the temperature more than $200^{\circ} \mathrm{C}$, the sensitivity decreases and attains 1.15 at $225^{\circ} \mathrm{C}$. Considering the temperature-dependent sensitivity studies, optimal operating temperature of $200^{\circ} \mathrm{C}$ was chosen to further examine the characteristics of the gas sensor to $\mathrm{NO}_{2}$ and $\mathrm{H}_{2} \mathrm{~S}$ gas. Comparing the maximum sensitivity values (3.32 for $7 \mathrm{ppm} \mathrm{NO}_{2}$ and 1.4 for $18 \mathrm{ppm} \mathrm{H}_{2} \mathrm{~S}$ ), $\mathrm{ZnO}$ sensor is more sensitive to $\mathrm{NO}_{2}$ at lower concentration and operating temperature. Figure $7 \mathrm{a}$ and $\mathrm{b}$ shows response of sensor to $7 \mathrm{ppm} \mathrm{NO}_{2}$ and $18 \mathrm{ppm} \mathrm{H}_{2} \mathrm{~S}$ gas at $200^{\circ} \mathrm{C}$, respectively.

The maximum sensitivity of $\mathrm{ZnO}$ being obtained at $200^{\circ} \mathrm{C}$, the dynamic responses of $\mathrm{ZnO}$ thin film gas sensor at $200^{\circ} \mathrm{C}$ were tested with different $\mathrm{NO}_{2}$ concentrations at 1.5, 3.5 and $30 \mathrm{ppm}$, respectively. Figure 8 represents the dynamic response of sensor to different $\mathrm{NO}_{2}$ gas concentration studied. Dynamic responses of the sensor to 5, 10, 30 and $60 \mathrm{ppm}$ concentration of $\mathrm{H}_{2} \mathrm{~S}$ gas were performed at the

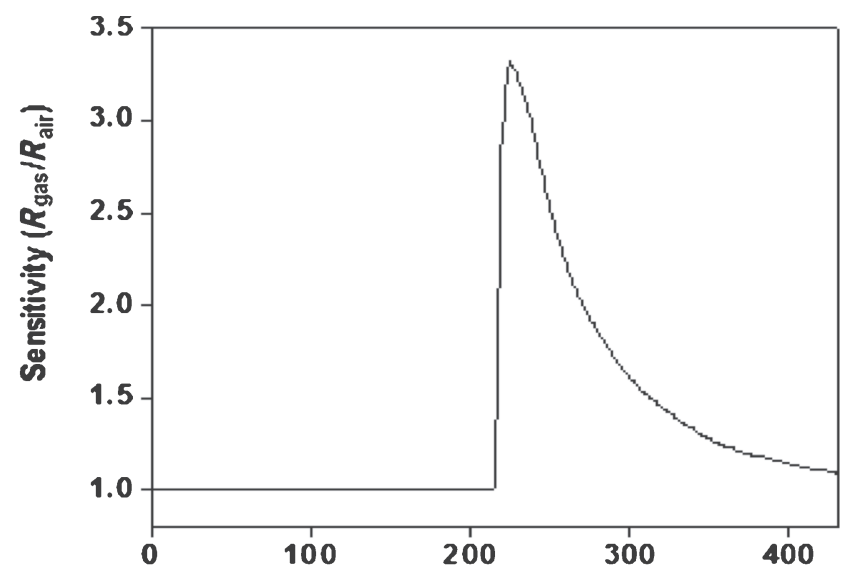

(a)

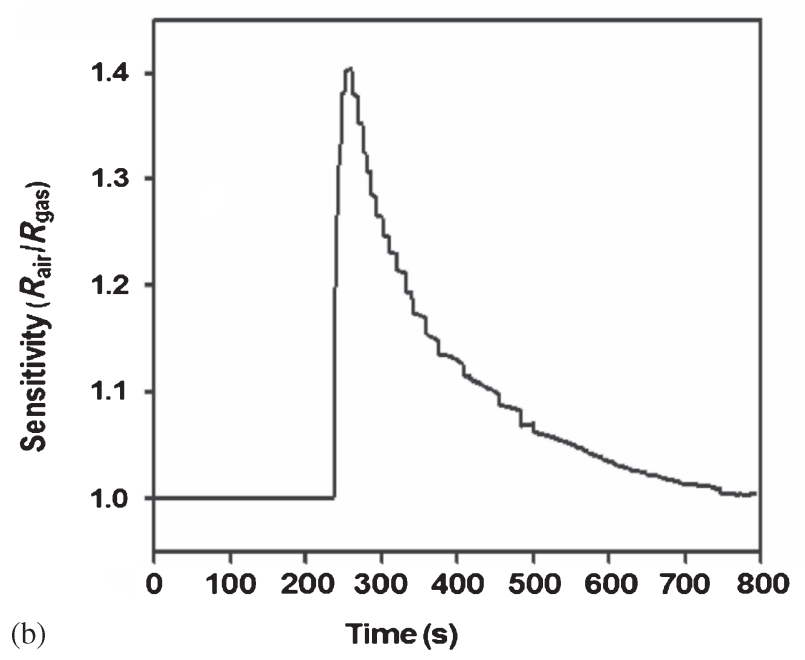

Figure 7. Response of $\mathrm{ZnO}$ thin film sensor to (a) $7 \mathrm{ppm} \mathrm{NO}_{2}$ gas and (b) $18 \mathrm{ppm} \mathrm{H}_{2} \mathrm{~S}$ gas at $200^{\circ} \mathrm{C}$. optimum operating temperature of $200^{\circ} \mathrm{C}$. Figure 9 represents the dynamic response of the sensor to $\mathrm{H}_{2} \mathrm{~S}$ gas at $200^{\circ} \mathrm{C}$ to various concentrations.

Chemoresistivity is the basis of sensing mechanism for metal oxides, which consists of a variation of intergranular and intragranular barriers with subsequent conductance change, as a response to surface chemical reactions with environmental gases. $\mathrm{ZnO}$-based gas elements prepared in nanocrystalline form have large numbers of grain boundaries and necks. The adsorbed oxygen on the grain surface extracts the conduction electrons from near-surface region of the grain, leading to the grain-boundary barriers and the neck barriers. ${ }^{63}$ The neck barrier controls the electron conducting channel through the neck and the electron density in the space charge layer at the neck. ${ }^{64}$ Therefore the neck barrier

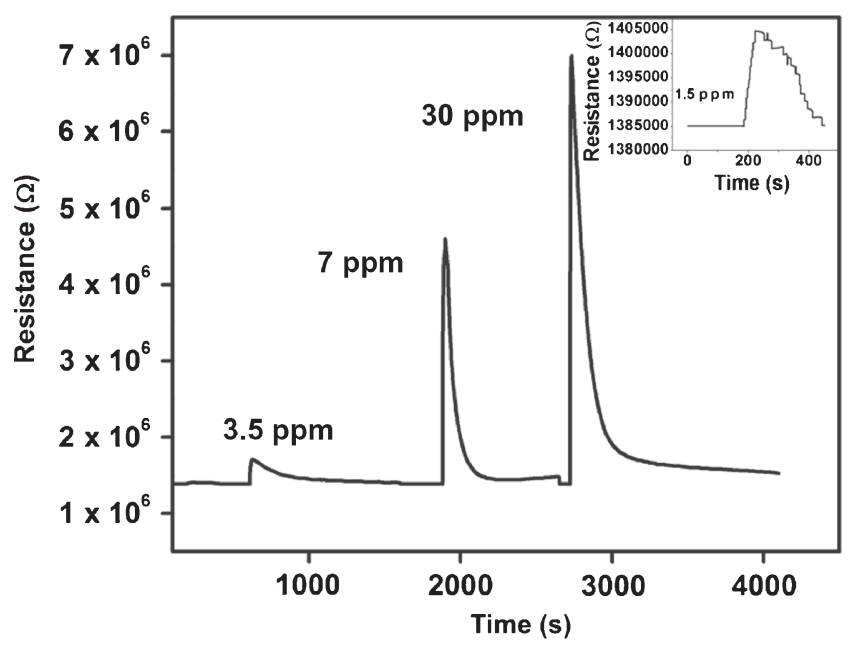

Figure 8. Dynamic response of $\mathrm{ZnO}$ thin film sensor to different $\mathrm{NO}_{2}$ gas concentrations studied.

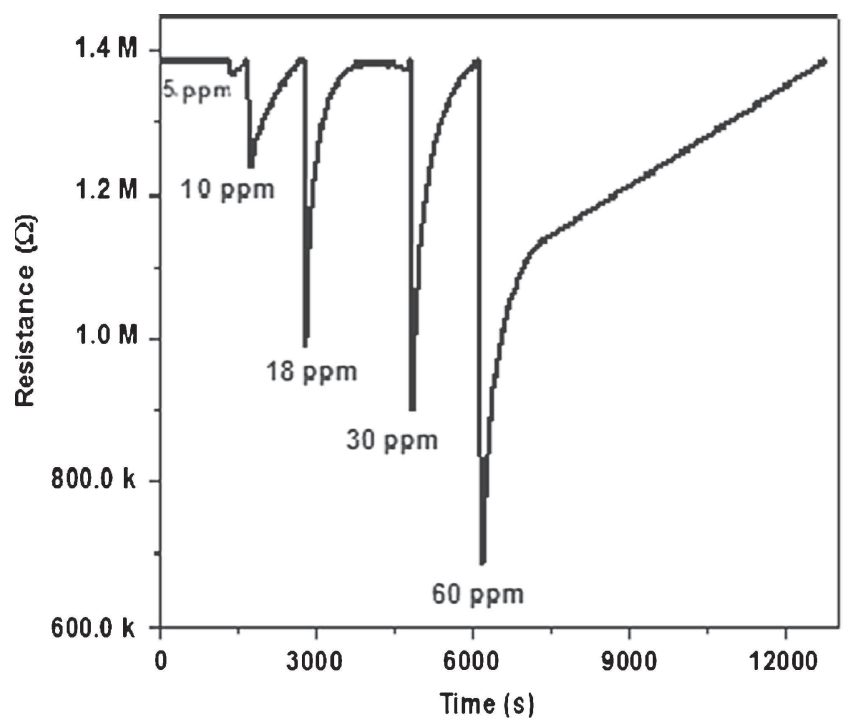

Figure 9. Dynamic response of thin film sensor to different $\mathrm{H}_{2} \mathrm{~S}$ gas concentrations studied. 
determines the neck resistance. At the same time, the grainboundary barrier determines the grain-boundary resistance. Ma et $a l^{63}$ studied the effect of grain size on gas sensitivity on $\mathrm{ZnO}{ }^{65}$ This group described the total sensitivity in $\mathrm{ZnO}$ based nanocrystalline sensors is the effect of both neck and the neck-grain boundary resistance. Gupta et $a l^{65}$ studied the sensitivity of $\mathrm{ZnO}$-based gas sensors to $\mathrm{NO}$ and $\mathrm{H}_{2} \mathrm{~S}$ gas. The results demonstrate that response of $\mathrm{ZnO}$ sensors to $\mathrm{H}_{2} \mathrm{~S}$ arises from grain boundary only, whereas both grain boundaries and intra-grain resistances contribute towards response to NO. As XRD studies confirmed the nanocrystalline nature, a similar effect is expected in our sensors to $\mathrm{NO}_{2}$ and $\mathrm{H}_{2} \mathrm{~S}$ gases. However, detailed investigations like impedance spectroscopy measurements are to be carried out to confirm these findings.

Oxygen vacancies and defects in lattice act as adsorption sites for oxygen and test gases. As the detection of gases originates from interaction of these adsorbed oxygen atomswith gases, maximum (minimum) defect density in (polycrystalline material) yields maximum (minimum) response. ${ }^{65}$ Raman spectroscopy performed on our sensors revealed that the thin film sensors prepared are oxygen deficient. These oxygen vacancies in the sensors act as additional sites for gas adsorption, there by enhancing the sensitivity.

Earlier research works conclude, oxygen adsorbed on the surface of oxide gas sensors undergoes the following reactions given by ${ }^{66}$ eqs $(2-5)$.

$$
\begin{aligned}
& \mathrm{O}_{2 \text { (gas) }} \leftrightarrow \mathrm{O}_{2} \text { (ads), } \\
& \mathrm{O}_{2 \text { (ads) }}+\mathrm{e}^{-} \leftrightarrow \mathrm{O}_{2}^{-} \text {(ads), } \\
& \mathrm{O}_{2 \text { (ads) }}+2 \mathrm{e}^{-} \leftrightarrow 2 \mathrm{O}^{-}{ }_{\text {(ads) }}, \\
& \mathrm{O}^{-}{ }_{\text {(ads) }}+\mathrm{e}^{-} \leftrightarrow \mathrm{O}_{2}^{-} \text {(ads) } .
\end{aligned}
$$

At low temperatures, $\mathrm{O}_{2}^{-}$is commonly chemisorbed. At high temperatures, however, $\mathrm{O}^{-}$and $\mathrm{O}^{2-}$ are chemisorbed while $\mathrm{O}_{2}^{-}$disappears. ${ }^{67}$ The oxygen ionosorption removes conduction electrons and thus lowers the conductance of $\mathrm{ZnO} .{ }^{67}$ The reactive oxygen species such as $\mathrm{O}^{2-}, \mathrm{O}_{2}^{-}$and $\mathrm{O}^{-}$are first adsorbed on $\mathrm{ZnO}$ surface when temperature rises. When the sensor film is exposed to $\mathrm{NO}_{2}$, which is an oxidizing gas, the molecules can be directly adsorbed onto the surface by extracting electrons from the conduction band (eq. (6)) or they can interact with the chemisorbed oxygen on the surface (eqs (7 and 8))

$$
\begin{aligned}
& \mathrm{NO}_{2(\mathrm{~g})}+\mathrm{e}^{-} \rightarrow \mathrm{NO}_{2}^{-} \text {(ads), } \\
& \mathrm{NO}_{2(\mathrm{~g})}+\mathrm{O}_{2}^{-} \text {(ads) }+2 \mathrm{e}^{-} \rightarrow \mathrm{NO}_{2}^{-} \text {(ads) }+2 \mathrm{O}^{-}{ }_{(\mathrm{ads})}, \\
& \mathrm{NO}_{2}^{-} \text {(ads) }+\mathrm{O}_{2}^{-} \text {(ads) } \rightarrow 2 \mathrm{O}^{-}{ }_{(\text {ads })}+\mathrm{NO}_{2} .
\end{aligned}
$$

As shown in above equations the electrons are consumed in the reactions, which explain the increase of the $\mathrm{ZnO}$ resistance after the $\mathrm{NO}_{2}$ exposure. The adsorption of $\mathrm{O}_{2}^{-}$ions is a very interesting and critical phenomenon in metal-oxide gas sensor, because the $\mathrm{O}_{2}^{-}$ions tend to assist the adsorbed $\mathrm{NO}^{2-}$ ions in taking the electrons from the $\mathrm{ZnO}$ thin films.

The optimum operating temperature for pure and doped sensors was found to be $200^{\circ} \mathrm{C}$ for $\mathrm{NO}_{2}$ gas. At lower temperature the sensitivity was low; also the recovery time kept on increasing, which indicates a longer time taken by the sensor to revert back to its base-line properties for the next operation. At low operating temperature sensitivity of the films to $\mathrm{NO}_{2}$ is restricted by the speed of the chemical reaction, because the electrons do not have enough thermal energy to react with the surface adsorbed oxygen species. In fact, during adsorption of atmospheric oxygen on the film surface, a potential barrier to charge transport is developed. As operating temperature increases the thermal energy obtained is high enough to overcome the potential barrier and thus electron concentration increases significantly, which in turn leads to an increase in sensitivity of sensor films. At optimum operating temperature the sensitivity is maximum. This is attributed to the availability of sufficient adsorbed ionic species of oxygen on film surface, which react most effectively with $\mathrm{NO}_{2}$ molecules at this particular temperature. The results obtained for $\mathrm{NO}_{2}$ gas sensing is comparable with earlier published results. ${ }^{68,69}$

A reverse effect is observed when the sensor films are exposed to $\mathrm{H}_{2} \mathrm{~S}$ gas, a decrease of the $\mathrm{ZnO}$ film resistance under $\mathrm{H}_{2} \mathrm{~S}$ exposure, which can be explained by its reaction with chemisorbed oxygen (eqs (9 and 11)), inducing the release of electrons in the conduction band. ${ }^{70}$ The gas response by MOS, in general, can be described as

$$
\begin{aligned}
& \mathrm{H}_{2} \mathrm{~S}_{\text {(gas) }}+\mathrm{O}_{2 \text { (ads) }}^{-} \leftrightarrow \mathrm{H}_{2} \mathrm{~S}_{\text {(ads) }}+\mathrm{O}_{2 \text { (gas) }}+\mathrm{e}^{-}, \\
& 2 \mathrm{H}_{2} \mathrm{~S}+3 \mathrm{O}_{2 \text { (ads) }}^{-} \leftrightarrow 2 \mathrm{SO}_{2}+2 \mathrm{H}_{2} \mathrm{O}+3 \mathrm{e}^{-} .
\end{aligned}
$$

This reaction shows an increase in the number of electrons (the reaction infuses electrons into sensing layers), thereby decreasing the sensor resistance. In addition to surface reaction with adsorbed oxygen species, chemical conversion of $\mathrm{ZnO}$ with $\mathrm{H}_{2} \mathrm{~S}$ is another possible reaction mechanism affecting conductivity of $\mathrm{ZnO}$ sensor. The chemical conversion of gas sensing materials through the direct reaction with target gas is known to be an important mechanism that changes the conductivity and produces a high sensitivity in several sensing materials of metal oxides. The chemical conversion of $\mathrm{CuO}$ nanoparticle to metallic copper sulphide $(\mathrm{CuS})$ has been reported in $\mathrm{H}_{2} \mathrm{~S}$ sensing by Xue et $a l^{71}$ and formation of $\mathrm{AuS}$ by reaction of $\mathrm{H}_{2} \mathrm{~S}$ on the gold nanoparticles was also reported by Shirsat et al. ${ }^{72}$ Moreover, various types of complex reactions between $\mathrm{ZnO}$ and sulphur compounds $\left(\mathrm{SO}_{x}\right.$, $\mathrm{H}_{2} \mathrm{~S},\left(\mathrm{NH}_{4}\right)_{2} \mathrm{~S}$ and so on.) have been reported from surface chemistry studies on $\mathrm{ZnO} .^{73-76} \mathrm{Kim}$ et $\mathrm{al}^{77}$ reported the formation of $\mathrm{ZnS}$ on the surface of $\mathrm{ZnO}$ on exposure to $\mathrm{H}_{2} \mathrm{~S}$ gas at a temperature above $300^{\circ} \mathrm{C}$. The XPS studies revealed that at temperature above $300^{\circ} \mathrm{C}$, beside surface reaction with oxygen, $\mathrm{H}_{2} \mathrm{~S}$ also decomposes to form $\mathrm{Zn}-\mathrm{S}$ bonds in $\mathrm{ZnO}$; this change causes the formation of a shallow donor level and causes a drastic increase in conductivity. Wang et al ${ }^{78}$ studied 
the sensitivity of $\mathrm{ZnO}$ to $\mathrm{H}_{2} \mathrm{~S}$ gas in the temperature range of $100-450^{\circ} \mathrm{C}$ and reported the sulphuration of $\mathrm{ZnO}$ surface on exposure to $\mathrm{H}_{2} \mathrm{~S}$ gas. When the sensor was exposed to $\mathrm{H}_{2} \mathrm{~S}$ gas, the transformation of highly resistive $\mathrm{ZnO}$ into wellconducting $\mathrm{ZnS}$ led to the decrease of electrical resistance. The reactions in the response and recovery processes can be represented as follows:

$$
\begin{aligned}
& \mathrm{ZnO}(\mathrm{s})+\mathrm{H}_{2} \mathrm{~S}(\mathrm{~g}) \rightarrow \mathrm{ZnS}(\mathrm{s})+\mathrm{H}_{2} \mathrm{O}(\mathrm{g}), \\
& 2 \mathrm{ZnS}(\mathrm{s})+3 \mathrm{O}_{2}(\mathrm{~g}) \rightarrow 2 \mathrm{ZnO}(\mathrm{s})+2 \mathrm{SO}_{2}(\mathrm{~g}) .
\end{aligned}
$$

The Gibbs free energy, enthalpy and entropy for both sulphuration and desulphuration were calculated by the group and the results showed that both reactions are spontaneous. We expect the same kind of sulphuration process in our $\mathrm{ZnO}$ thin film $\mathrm{H}_{2} \mathrm{~S}$ sensors along with the reaction of $\mathrm{H}_{2} \mathrm{~S}$ with oxygen adsorbates, thereby decreasing sensor resistance in the presence of $\mathrm{H}_{2} \mathrm{~S}$ gas.

Response and recovery times are important parameters for designing sensors for desired application. Response/recovery times are defined as the time required for absorption and desorption of the oxygen on, or from the sensor surface to reach the saturation or to reduce the conductivity back to the
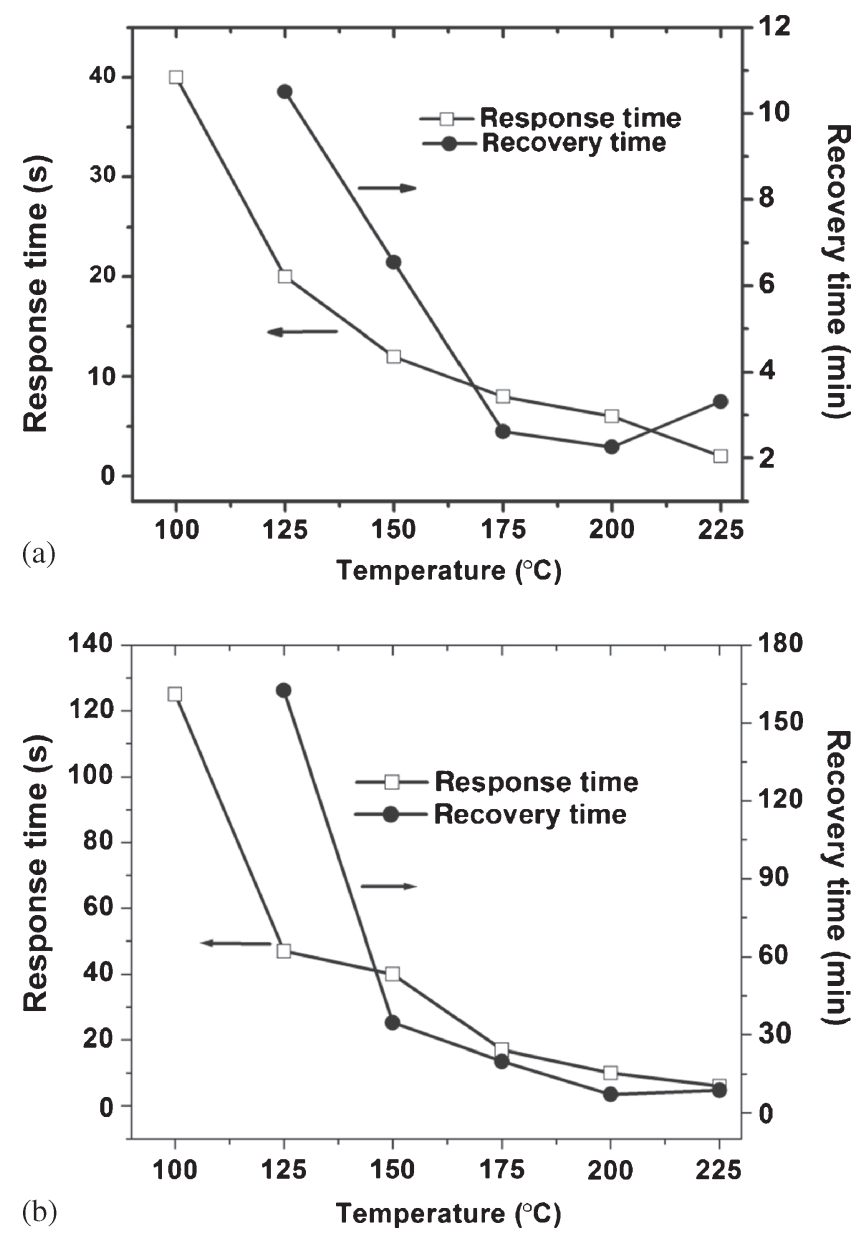

Figure 10. Response and recovery time of $\mathrm{ZnO}$ thin film sensor to (a) $7 \mathrm{ppm} \mathrm{NO} \mathrm{N}_{2}$ gas (b) $18 \mathrm{ppm} \mathrm{H}_{2} \mathrm{~S}$ gas at different temperature. baseline conductance. Response time of a sensor can vary from seconds to minutes, but a good sensor is the one that shows a short response and recovery time. In our work, response time of sensor was defined as time required for sensor resistance to reach $90 \%$ of maximum resistance. Recovery time was defined as time necessary for the sensor to return to $10 \%$ of its original resistance (before introduction of gas). Response and recovery time of $\mathrm{ZnO}$ sensor to $7 \mathrm{ppm} \mathrm{NO}_{2}$ and $18 \mathrm{ppm} \mathrm{H}_{2} \mathrm{~S}$ gas at the temperature range of $100-225^{\circ} \mathrm{C}$ was recorded and is shown in figure $10 \mathrm{a}$ and $\mathrm{b}$. At optimum temperature of $200^{\circ} \mathrm{C}$, the response time of $\mathrm{ZnO}$ sensor was 6 and $10 \mathrm{~s}$ to $\mathrm{NO}_{2}$ and $\mathrm{H}_{2} \mathrm{~S}$ gases, respectively. The recovery time recorded was 2.3 and 7 min to $\mathrm{NO}_{2}$ and $\mathrm{H}_{2} \mathrm{~S}$ gases respectively. The response and recovery time obtained for $\mathrm{ZnO}$ sensor to $\mathrm{NO}_{2}$ gas is comparable with earlier published results. ${ }^{44,68,79,80}$ Compared to $\mathrm{NO}_{2}$ measurements it is seen that the recovery characteristics are very slow for $\mathrm{H}_{2} \mathrm{~S}$ measurements. This may be due to slow desulphuration process on the surface of sensors resulting in larger recovery time.

\section{Conclusion}

$\mathrm{ZnO}$ thin film sensors were fabricated by spray pyrolysis technique. The prepared films were annealed at $600^{\circ} \mathrm{C}$ overnight prior to gas sensing measurements. The XRD analysis confirmed the nanocrystalline nature of the annealed sensor. The average particle size was found to be $38 \mathrm{~nm}$. The crystalline structure was found to be hexagonal wruzite in nature. Surface morphological studies performed with SEM revealed closely packed arrangement of crystallites. Elemental analysis were performed using EDS. Raman spectroscopy studies confirmed the $\mathrm{ZnO}$ hexagonal wurtzite structure. Raman studies established the oxygen deficient nature of thin film sensor, which has an added advantage for gas sensing purposes. Gas sensing investigation of the prepared sensors was characterized with $\mathrm{NO}_{2}$ and $\mathrm{H}_{2} \mathrm{~S}$ gases. Thin film sensors were found to be more selective to $\mathrm{NO}_{2}$ gas at an optimum temperature of $200^{\circ} \mathrm{C}$. For a $7 \mathrm{ppm}$ concentration, the sensor sensitivity was 3.32 with a response and recovery time of $6 \mathrm{~s}$ and $2.26 \mathrm{~min}$, respectively. It is expected that the response to $\mathrm{H}_{2} \mathrm{~S}$ arises due to changes in grain boundary resistance, while that to $\mathrm{NO}_{2}$ arises due to changes in both intra-grain and grain boundary resistances. Oxygen vacancies in the lattice, as were also seen, enhance the sensor response. However, the exact details of these complicated surface reactions are yet to be fully understood. More detailed experimentation would be necessary to substantiate the suggestions speculated here. The results indicate that spray pyrolysis technique is a reliable method for the preparation of nanocrystalline zinc oxide films for gas sensor applications.

\section{Acknowledgements}

We wish to acknowledge Dr M K Jayaraj, Nanophotonic \& Optoelectronic Devices Laboratory, Department of Physics 
for Raman measurements under DST nano mission initiative programme. We are thankful to SAIF, Cochin University of Science and Technology, Kochi, Kerala, India, for the XRD and SEM measurements.

\section{References}

1. Do J S and Shieh R Y 1996 Sensors and Actuators B 3719

2. Hoheráková Z and Opekar F 2004 Sensors and Actuators B 97 379

3. Horrillo M C, Fernández M J, Fontecha J L, Sayago I, Garciá M, Aleixandre M, Gutiérrez J, Gràcia I and Cané C 2006 Sensors and Actuators B 118356

4. Ionescu R, Hoel A, Granqvist C G, Llobet E and Heszler P 2005 Sensors and Actuators B 104132

5. Comini E, Faglia G, Sberveglieri G, Pan Z and Wang Z L 2002 Appl. Phys. Lett. 811869

6. Yamazoe N 1991 Sensors and Actuators B 57

7. Chiou W T, Wu W Y and Ting J M 2003 Diamond Relat. Mater. 121841

8. Ibang E J, Le Luyer C and Mugnier J 2003 Mater. Chem. Phys. 80490

9. Penge W, He Yongning, Wen Changbao and Ke Ma 2012 Sensors and Actuators A: Physical 18434

10. Baxter J B and Aydil E S 2006 Sol. Energ. Mater. Sol. Cells 586607

11. Altamirano-Juárez D C, Torres-Delgado G, Jiménez-Sandoval S, Jiménez-Sandoval O and Castanedo-Pérez R 2004 Sol. Energ. Mater. Sol. Cells 8235

12. Lin F C, Yuji Takao, Yasuhiro Shimizu and Makoto Egashira 1995 Sensors and Actuators B 25843

13. Özgür Ü, Alivov Y I, Liu C, Teke A, Reshchikov M A, Dogan S, Avrutin V, Cho S J and Morkoc H 2005 J. Appl. Phys. 98 041301

14. Ryu Y R, Kim W J and White J H 2000 J. Cryst. Growth 219 419

15. Seiyama T and Kato A 1962 Anal. Chem. 341502

16. Zhang N, Yu K, Li Q, Zhu Z Q and Wan Q 2008 J. Appl. Phys. 103104305

17. Badadhe S S and Mulla I S 2009 Sensors and Actuators B $\mathbf{1 4 3}$ 164

18. Calestani D, Zha M, Mosca R, Zappettini A, Carotta M C, Di Natale V and Zanotti L 2010 Sensors and Actuators B 144472

19. Ramgir N S, Ghosh M, Veerender P, Datta N, Kaur M, Aswal D K and Gupta S K 2011 Sensors and Actuators B 156875

20. Shewale P S, Patil V B, Shin S W, Kim J H and Uplane M D 2013 Sensors and Actuators B 186226

21. Zhou Q, Weigen Chen, Lingna Xu and Shudi Peng 2013 Sensors 136171

22. Chen T P, Sheng-Po Chang, Fei-Yi Hung, Shoou-Jinn Chang, Zhan-Shuo Hu and Kuan-Jen Chen 2013 Sensors 133941

23. Xie C, Liqi Xiao, Mulin Hu, Zikui Bai, Xianping Xia and Dawen Zeng 2010 Sensors and Actuators B 145457

24. Chu X, Chen T, Zhang W, Zheng B and Shuia H 2009 Sensors and Actuators B $\mathbf{1 4 2} 49$

25. Han N, Chai L, Wang Q, Tian Y, Deng P and Chen Y 2010 Sensors and Actuators $B \mathbf{1 4 7} 525$
26. Liewhiran C and Phanichphant S 2007 Sensors 7650

27. Chou S M, Lay Gaik Teoh, Wei Hao Lai, Yen Hsun Su and Min Hsiung Hon 2006 Sensors 61420

28. Wang L, Yanfei Kang, Xianghong Liu, Shoumin Zhang, Weiping Huang and Shurong Wang 2012 Sensors and Actuators B 162237

29. Kim J and Yong K 2011 J. Phys. Chem. C 1157218

30. Talwar V, Onkar Singh and Ravi Chand Singh 2014 Sensors and Actuators B 191276

31. Raj V B, Nimal A T, Yashoda Parmar, Sharma M U, Sreenivas K and Vinay Gupta 2010 Sensors and Actuators B 147517

32. Mani G K and John Bosco Balaguru Rayappan 2013 Sensors and Actuators B 183459

33. Zeng Y, Zheng Lou, Lili Wang, Zou Bo, Tong Zhang, Weitao Zheng and Guangtian Zou 2011 Sensors and Actuators B 156 395

34. Tulliani J M, Alessio Cavalieri, Simone Musso, Eloisa Sardella and Francesco Geobaldo 2011 Sensors and Actuators B 152 144

35. Ali G M, Cody V T, Ali K J, Isam M A and James C M 2013 Sensors 1316801

36. Dhawale D S, Dubal D P, More A M, Gujar T P and Lokhande C D 2010 Sensors and Actuators B 147488

37. Gurav K V, Deshmukh P R and Lokhande C D 2011 Sensors and Actuators B 151365

38. Prajapati C S and Sahay P P 2011 Sensors and Actuators B 160 1043

39. Huang J, Haibo Ren, Pingping Sun, Cuiping Gu, Yufeng Sun and Jinhuai Liu 2013 Sensors and Actuators B 188249

40. Chen M, Wang Z, Han D, Gu F and Guo G 2011 Sensors and Actuators B 157565

41. Hung N L, Kim H, Hong S K and Kim D 2010 Sensors and Actuators B 151127

42. Rai P, Kim Y S, Song H M, Song M K and Yu Y T 2012 Sensors and Actuators B 165133

43. Kruefu V, Liewhiran C, Wisitsoraat A and Phanichphant S 2011 Sensors and Actuators B 156360

44. Chen I C, Shiu-Shiung Lin, Tsao-Jen Lin, Cheng-Liang Hsu, Ting Jen Hsueh and Tien-Yu Shieh 2010 Sensors 103057

45. Vimalkumar T V, Poornima N, Sudha Kartha C, Vijayakumar K P, Abe T and Kashiwaba Y 2010a Physica B 4054957

46. Vimalkumar $\mathrm{T}$ V, Poornima N, Sudha Kartha $\mathrm{C}$ and Vijayakumar K P 2010b Appl. Surf. Sci. 2566025

47. Vimalkumar $\mathrm{T}$ V, Poornima N, Sudha Kartha $\mathrm{C}$ and Vijayakumar K P 2010c Mater. Sci. Eng. B 17529

48. Vimalkumar T V, Poornima N, Jinesh K B, Sudha Kartha C and Vijayakumar K P 2011 Appl. Surf. Sci. 2578334

49. Fan X M, Lian J S, Guo Z X and Lu H J 2005 J. Cryst. Growth 279447

50. Park K S and Park J K 1999 Acta Mater. 472177

51. Charpentier C, Prod'homme P, Maurin I, Chaigneau M and Cabarrocas P R 2011 EPJ Photovoltaics 225002

52. Minami T, Sato H, Nanto H and Takata S 1984 Jpn. J. Appl. Phys. 24 L781

53. Zhou H, Chen L, Malik V, Knies C, Hofmann D M, Bhatti K P, Chaudhary S, Klar P J, Heimbrod W, Klingshirn C and Kalt H 2007 Phys. Status Solidi A 204112 
54. Wang J Z, Peres M, Soares J, Gorochov O, Barradas N P, Alves E, Lewis J E, Fortunato E, Neves A and Monteiro T $2005 \mathrm{~J}$. Phys. Condens. Matter 171719

55. Lin K F, Cheng H M, Hsu H C and Hsieh W F 2006 Appl. Phys. Lett. 88263117

56. Alim K A, Fonoberov V A, Shamsa M and Balandin A A 2005 J. Appl. Phys. 97124313

57. Lo S S, Huang D, Tu C H, Hou C H and Chen C C $2009 \mathrm{~J}$. Phys. D: Appl. Phys. 42095420

58. Xu X L, Lau S P and Tay B K 2001 Thin Solid Films 398244

59. Xu X L, Lau S P, Chen J S, Chen G Y and Tay B K $2001 J$. Cryst. Growth 223201

60. Rajalakshmi M, Arora A K, Bendre B S and Mahamuni S 2000 J. Appl. Phys. 872445

61. Damen T C, Porto S P S and Tell B 1966 Phys. Rev. 142570

62. Calleja J M and Cardona M 1977 Phys. Rev. B 163753

63. Ma Y, Wang W L, Liao K J and Kong C Y 2002 J. Wide Bandgap Mater. 10113

64. Xu C, Tamaki J, Miura N and Yamazoe N 1991 Sensors and Actuators B 3147

65. Gupta S K, Aditee Joshi and Manmeet Kaur 2010 J. Chem. Sci. 12257

66. Wang Y, Chen J and Wu X 2001 Mater. Lett. 49361

67. Kohl D 1990 Sensors and Actuators B 1158
68. Tamaekong N, Chaikarn Liewhiran, Anurat Wisitsoraat and Sukon Phanichphant 2010 Sensors 107863

69. Ghimbeu C M, Joop Schoonman, Martine Lumbreras and Maryam Siadat 2007 Appl. Surf. Sci. 2537483

70. Arshak K and Gaidan I 2005 Mater. Sci. Eng. B 11844

71. Xue X, Xing L, Chen Y, Shi S, Wang Y and Wang T $2008 \mathrm{~J}$. Phys. Chem. C 11212157

72. Shirsat D, Bangar M A, Deshusses M A, Myung N V and Mulchandani A 2009 Appl. Phys. Lett. 94083502

73. Chaturvedi S, Rodriguez J A, Jirsak T and Hrbek J 1998 J. Phys. Chem. B 1027033

74. Dloczik L, Engelhardt R, Ernst K, Fiechter S, Sieber I and Konenkamp R 2001 Appl. Phys. Lett. 783687

75. Rodriguez J A, Jirsak T, Chaturvedi S and Kuhn M 1999 Surf. Sci. 442400

76. Uhlrich J J, Franking R, Hamers J and Kuech T F 2009 J. Phys. Chem. C $\mathbf{1 1 3} 21147$

77. Kim K M, Hae-Ryong Kim, Kwon-Il Choi, Hyo-Joong Kim and Jong-Heun Lee 2011 Sensors 119685

78. Wang D, Chu X and Gong M 2007 Nanotechnology 18185601

79. Kim K M, Hyun-Mook Jeong, Hae-Ryong Kim, Kwon-Il Choi, Hyo-Joong Kim and Jong-Heun Lee 2012 Sensors 128013

80. Navale S C, Ravia V, Mulla I S, Gosavi S W and Kulkarni S K 2007 Sensors and Actuators B 126382 